\title{
Investigating Chronotype Orientation on Daily and Weekly Rhythm Fluctuations in Preschoolers Working Memory Performance
}

\author{
Zohre Nasiri Zarch ${ }^{1}$, Massoud Sharifi ${ }^{*}$, Mahmood Heidari², Shahla Pakdaman ${ }^{2}$ \\ ${ }^{1}$ PhD Student in Educational Psychology, Shahid Beheshti University, Tehran, Iran \\ ${ }^{2}$ Department of Psychology, Shahid Beheshti University, Tehran, Iran
}

\begin{abstract}
Background: Chronopsychology researches claim that cognitive processes performance during learning in the educational environment in times of the day and days of the week fluctuate, and working memory is essential among these cognitive processes. The research aimed to study the rhythm of daily and weekly working memory performance of preschoolers based on their chronotype (morningness and eveningness) orientation.

Methods: The research method is causal-comparative. The participants are 100 preschool children in Tehran that were selected based on purposive sampling. Their working memory was tested at different time intervals of $(8,11,13$, and 15) and weekly (Saturday, Sunday, Monday, Tuesday and Wednesday). Saturday also considered as the first day of the week. Data collection instrument were children morningness-eveningness preference (CMEP) in the form of questionnaire and working memory test. Data analysis based on a mixed analysis of variance.

Results: The results showed that preschoolers working memory performance during different days of the week and time of day was different $(P<0.01)$. There was a significant difference between children in different groups regarding memory at different hours of the day, but on different days of the week, there was no significant difference in memory performance $(P<0.01)$.

Conclusion: According to the findings, teachers and clinicians are suggested to consider the importance of circadian rhythm parameters in assessing cognitive function in patients and healthy people. Awareness of individual differences of the morningness-eveningness type can be very effective in designing training programs and preventive health associated matters with each type.

Keywords: Chronopsychology; Chronotype; Fluctuation, Daily and weekly rhythm; Working memory.
\end{abstract}

*Correspondence to Massoud Sharifi, Assistant Professor of Psychology, Department of Psychology, Shahid Beheshti University, Tehran, Iran.

Email: m-charifi@sbu.ac.ir

Published online 20 December 2018

Citation: S. Investigating chronotype orientation on Daily and weekly rhythm fluctuations in preschoolers working memory performance. Int Clin Neurosci J. 2018;5(4):150-157. doi:10.15171/icnj.2018.27.

\section{Introduction}

Performance comprises cognitive functions ranging in complexity from simple psychomotor reaction time to logical reasoning, working memory and complex executive functions. ${ }^{1}$ Memory is a kind of mental activity that allows one to preserve the states of consciousness such as trends, pains, desires, needs, feelings, sensory inputs, ideas and judgments and preserve and retrieve them in his mind and also gives the possibility of recognition to the individual. Memory also refers to the ability of the brain in accumulation, storage, encoding and remembering information, as well. ${ }^{2}$ Memory construct in the field of psychological studies illuminates how to store, record and organize different and various themes and checks the internal mental processing of recovery and oblivion. ${ }^{3,4}$ Biological rhythms are amongst the variables affecting memory function. Biological rhythms are the collection of ongoing biological activities that their course and scope are significant that are repeated at least at two consecutive quarters. The rhythms are ultradian rhythms, circadian rhythms and infradian rhythms. ${ }^{5}$ Understanding the fundamental principles of the circadian cycle and physiology of sleepwake helps us to know how the circadian system change human cognition processes and how it affects learning, memory, and emotion. ${ }^{6}$ The role of the circadian system in memory stabilization and improvement has neglected in this respect. Learning sequence varies with the time of day and night when there is sleep deprivation and then improves after REM sleep improved. ${ }^{7,8}$ Day and night cycle in memory tasks have reported. ${ }^{9-13}$ Several studies also show that different organisms' capabilities influenced by days, weeks, months and even seasons. Alexander (4th century BC) mentions that the leaves of some trees open

(C) 2018 The Author(s). This is an open access article distributed under the terms of the Creative Commons Attribution License (http:// creativecommons.org/licenses/by/4.0/), which permits unrestricted use, distribution, and reproduction in any medium, provided the original work is properly cited. 
in the morning and close at nights. Von Frisch observed that bees on flowers sit only at certain times. ${ }^{11}$ Cognitive performance parameters are time-dependent. Cognitive function reduces in the morning (from 9 to $11 \mathrm{AM}$ ). Then, in the early hours afternoon, ${ }^{2}$ increase and reach its peak by the end of the evening (4 PM). Previous studies have reported the significant impact of circadian rhythms on academic performance, which confirms the idea that different cognitive abilities, such as memory influenced by circadian rhythm., ${ }^{9,14}$

In addition to the circadian cycle, the sleep-wake cycle is another factor affecting the emotional and cognitive functions. In the science of morphology, time divided into 3 sets (1) morning, (2) afternoon and (3) neutral. ${ }^{15,16}$ Time changes in cognitive processes may occur for many people so that those hours are considered optimal hours for the cognitive process. ${ }^{17}$ Investigating daily fluctuations and cognitive performance or as it can be called school rhythm can help to find the most optimal times for learning during the day, So that during the day there are differences between individuals in the learning process. These time differences change and fluctuate between girls and boys in different age groups. ${ }^{12}$ These changes have also witnessed in the puberty period. ${ }^{18}$ Circadian variation in human behavior has been depicted in activities such as sleep-wake upcycle, mental alertness report, sleepiness and fatigue, and performance on some activities such as sensory and motor functions, time conception, reaction time, memory function, verbal performance, mathematical performance, driving and job. ${ }^{19}$ In general, the reason that performance boosts during the day and reduces at night associated with changes in body temperature. The performance also depends to a biological factor in the decrease in memory function in the waking hours or during sleep deprivation. This bioregulation also improves the performance after sleep. ${ }^{5,20}$

Although there have been many types of research in the field of biological rhythms and their impact on cognitive processes, particularly memory, no research has investigated these variables taking into account the chronotype (morningness and eveningness) simultaneously which can consider as the innovative aspect of this research in Iran and even abroad. This study aims to find if (1) Does the memory function of preschool children differ throughout different time and different days of the week in an educational environment? (2) Is memory performance of a morning preschool children different from afternoon preschool children and these two time periods throughout the day and the week?

\section{Methods}

The research aimed to study the rhythm of daily and weekly working memory performance of preschoolers based on their chronotype (morningness and eveningness) orientation. The research method is causal-comparative.
The statistical population is 100 preschool children in Tehran that were selected based on purposive sampling. The researcher started to find a school with both morning and evening shifts in Tehran and could finally select the suitable school which fitted the purpose of data collection. Data collection instrument were children morningness-eveningness preference (CMEP) in the form of questionnaire and working memory test. To achieve the desired outcome a group of students selected from morning shift preschoolers, a group selected from evening shift, and the third group selected from both morning and evening shift. The logic behind the estimation of sample size and the causal-comparative nature of the study determines the inclusion of at least 15 participants in each group. Also, using the software to determine sample size, $G^{*}$ Power version of 10.0.3 in the family $F$ with the input of the effect size 0.33 , alpha level 0.05 , power 0.95 , resulted in a sample size of 98 in this study. The total participants were 100 preschool children. Their working memory was tested at different time intervals of $(8,11,13$, and 15) and weekly (Saturday, Sunday, Monday, Tuesday and Wednesday). Saturday also considered as the first day of the week. After obtaining written consent from parents of children participating in the study, demographic questionnaire and the morning-evening scale presented to them. In the phase of implementing the study, the researcher visited the mentioned center in the intervals between 8:00 AM and 9:00 AM, 10:00 $\mathrm{AM}$ and 11:00 AM, 1:00 PM and 2:00 PM, 3:00 PM and 4:00 PM to assess the cognitive abilities of working memory in children. This assessment was repeated 5 days a week, from Saturday to Wednesday. Assessment tools used by the researchers conducted by the instructions. SPSS software version 23 using a mixed analysis of variance was employed.

\section{Measures}

\section{Morningness-Eveningness Questionnaire}

Children's Chronotype Questionnaire (CCTQ) employed to measure the morningness-eveningness orientation among preschool children. CCTQ is adapted from previous questionnaires to assess the morningness/ eveningness $(\mathrm{M} / \mathrm{E})$ scale prepared by Werner et al. ${ }^{21}$ The CCTQ is a parent-report questionnaire which includes 3 different parent-report measures of children's chronotype. The M/E scale score derived from responses to 10 questions about preferred timing of going to bed, getting up in the morning, taking a cognitive test, and completing physical activities, as well as the child's most prevalent behavior in recent weeks (e.g., sleepiness after awakened in the morning and in the evening). Scoring of questions 1, 2, 8 and 9 done in reverse. M/E scalescores range from 10 (extreme morningness) to 49 (extreme eveningness). Morning types classified by an $\mathrm{M} / \mathrm{E}$ scale score of less than 23 , intermediate types by a score of 24-32, and evening types by a score of more than33. Werner and et $\mathrm{al}^{21}$ reported Cronbach's alpha of 
the scale 0.81 which was in line with the alpha reported by Carskadon et al. ${ }^{22}$ The average corrected correlation with the total scale of each question was 0.31 ranging from 0.49 to 0.71 , respectively. ${ }^{22}$ These indicators suggest that the validity and internal consistency of this scale are desirable. To use this scale in this study, at first scale questions were translated by English into Farsi translator and then translated back into English. After proofreading, the Persian questionnaire was revised again and handed to some psychology professor for checking its content validity.

\section{Working Memory Test}

To measure working memory in children, based on Kim Karad visual memory test, a visual-verbal reminders paradigm used. At first 15 images of animals, fruits and objects from the collection of images were randomly selected to conduct a pilot study with 15 images for the ultimate test. After that, at first, the most recognizable images in the pilot study were determined for samples and images that not identified and excluded from them. Then 15 of these images, which had the highest optimal variance among children, were selected. The test run in 3 phases, in each phase 5 images are presented to children for 15 seconds. At the same time children see the images the instructor tells them the word and wants them to repeat. After completion of the images, children distorted in a play for 30 seconds. Then they are asked to name the pictures that express their view. The number of images that children remind in 3 steps considers as their score from zero to 15 .

\section{Results}

Mean and standard deviation of memory test at different times of day and days of the week for children in 3 groups presented in Table 1 (for the sake of brevity, the report columns and rows corresponding to the total score ignored).

To answer the research question we used mixed analysis of variance. Because there were an independent variable, 2 independent variables within the group, 2 independent variables within the group and a dependent variable to measure the distance. Independent variable included: group of children at 3 levels: in the morning, intermediate and evening. Two independent variables within the group were: daily cycle with 4 levels: 8 hours, 11 hours, 13 hours and hours 15, and a weekly cycle with 5 levels: Saturday, Sunday, Monday, Tuesday and Wednesday. Dependent variable to measure the distance was memory score. Before carrying out the analysis, for the assumption of sphericity Mauchly test was used which the results tabulated in Table 2.

According to the Mauchly test results provided in Table 2 , the assumption of sphericity for the main effects in both within-subjects variables established. The chi-square value is significant for the effect of their interactions shows that this assumption does not connect to the interactive effect of daily and weekly cycles. Thus, in calculating the interaction between the two variables within-subjects analysis of variance for the effect of Greenhouse-Geysers corrected values used.

The combined analysis of variance in Table 3 shows the effect of the weekly cycle on memory function in preschool children is significant, which means that the memory of these children significantly differs during different days of the week. Bonferroni post hoc test revealed that the difference between Saturday with Tuesday and Wednesday and also between Sunday and Wednesday is significant. Figure 1 shows the weekly cycle effect on memory performance in preschool children.

As Figure 1 represents, memory function of preschoolers on Saturday and Sunday is at its highest point and reaches

Table 1. The Mean and Standard Deviation of Children's Memory in 3 Groups During Different Hours of the Days of the Week

\begin{tabular}{|c|c|c|c|c|c|c|c|c|c|}
\hline \multirow{3}{*}{ Group } & \multirow{3}{*}{ Days of Weak } & \multicolumn{8}{|c|}{ Day's Hours } \\
\hline & & \multicolumn{2}{|c|}{8} & \multicolumn{2}{|c|}{10} & \multicolumn{2}{|c|}{13} & \multicolumn{2}{|c|}{15} \\
\hline & & Mean & SD & Mean & SD & Mean & SD & Mean & SD \\
\hline \multirow{5}{*}{ Morning } & Saturday & 9.24 & 2.25 & 6.71 & 2.46 & 7.29 & 2 & 6.18 & 2.6 \\
\hline & Sunday & 8.65 & 2.8 & 7.29 & 2.54 & 6.47 & 3.41 & 6.65 & 2 \\
\hline & Monday & 7.24 & 2.27 & 5.95 & 1.43 & 6.71 & 1.43 & 5.88 & 1.57 \\
\hline & Tuesday & 7.53 & 2.37 & 6 & 2 & 6 & 2 & 7.29 & 2.71 \\
\hline & Wednesday & 7.53 & 3.39 & 7.29 & 2 & 6.94 & 3.15 & 6.47 & 2 \\
\hline \multirow{5}{*}{ Intermediate } & Sa & 8.14 & 2.33 & 7.32 & 2.11 & 6.75 & 2.43 & 7.54 & 2.48 \\
\hline & $\mathrm{Su}$ & 7.44 & 2.36 & 6.7 & 2.42 & 7 & 2 & 7.68 & 2.77 \\
\hline & Mo & 7.72 & 2.18 & 6.37 & 2.24 & 6.47 & 2.61 & 6.72 & 2.61 \\
\hline & $\mathrm{Tu}$ & 7.4 & 2.8 & 7 & 2.73 & 6.18 & 2.3 & 7.11 & 2.3 \\
\hline & We & 6.93 & 2.5 & 6.42 & 2.77 & 5.95 & 2.84 & 7.12 & 2.68 \\
\hline \multirow{5}{*}{ Evening } & Sa & 7.38 & 2.62 & 7.1 & 2.86 & 7.19 & 1.44 & 7 & 3.28 \\
\hline & $\mathrm{Su}$ & 7.23 & 3.49 & 7.73 & 2.93 & 6.88 & 2.97 & 7.54 & 3.1 \\
\hline & Mo & 7.35 & 2 & 7.42 & 2.88 & 6.27 & 2 & 7 & 2.35 \\
\hline & $\mathrm{Tu}$ & 7.31 & 2.75 & 6.77 & 2.12 & 5.65 & 2.31 & 7.19 & 2.7 \\
\hline & We & 7.38 & 3 & 5.5 & 2.3 & 5.81 & 2.28 & 7.12 & 2.26 \\
\hline
\end{tabular}


Table 2. Mauchly Test Results for Examination of Memory Data's Sphericity

\begin{tabular}{|c|c|c|c|c|}
\hline Within-Subject Effect & Mauchly Test & Chi-Square & $d f$ & $P$ Value \\
\hline Weekly Cycle & 0.84 & 16.41 & 9 & 0.06 \\
\hline Daily Cycle & 0.89 & 10.28 & 5 & 0.07 \\
\hline Weekly Cycle*Daily Cycle & 0.22 & 138 & 77 & 0.001 \\
\hline
\end{tabular}

Table 3. The Results of Mixed Analysis Variance for the Difference Between 3 Groups of Memory Performance During Day and Week

\begin{tabular}{|c|c|c|c|c|c|c|}
\hline Source & Squares Sum & $d f$ & Squares Mean & $\boldsymbol{F}$ & $P$ Value & Eta Square \\
\hline Weekly cycle & 113 & 4 & 28.37 & 4.51 & 0.001 & 0.04 \\
\hline Weekly cycle*group & 39.11 & 8 & 4.89 & 0.78 & 0.62 & 0.01 \\
\hline Error & 2436 & 388 & 6.28 & & & \\
\hline Daily cycle & 272 & 3 & 90.71 & 19.6 & 0.001 & 0.17 \\
\hline Daily cycle*group & 71 & 6 & 11.9 & 2.57 & 0.05 & 0.05 \\
\hline Error & 1346 & 291 & 4.62 & & & \\
\hline Weekly cycle*daily cycle & 62 & 9.76 & 6.42 & 1.3 & 0.22 & 0.01 \\
\hline Weekly cycle*daily cycle*group & 150 & 19.52 & 7.71 & 1.57 & 0.05 & 0.03 \\
\hline Source & 4642 & 946.78 & 4.9 & & & \\
\hline
\end{tabular}

its lowest points over the last days of the weekend. Chi Eta also reported in Table 3 for the main effects of the weekly cycle suggest that about $4 \%$ of preschoolers memory change explained by the weekly cycle.

According to Table 3, it is evident that the interaction effect of the weekly cycle and groups on memory performance is not significant, which means that these two variables are not adjusted to each other and preschoolers' morning, intermediate and evening shifts do not show memory performance difference during different days of the week. However, the main effect on the daily cycle is significant. That is, preschoolers overall memory performance is different during different times of the day. Bonferroni post hoc test revealed that the difference between the hours of 8 to 11,13 and 15 and between 13 and 15 hours is significant. Figure 2 shows the daily cycle effect on preschoolers' memory performance.

As indicated in Figure 2, the memory function of preschoolers is at the highest level at 8 oclock and is at the lowest level at 13, but it has significantly improved

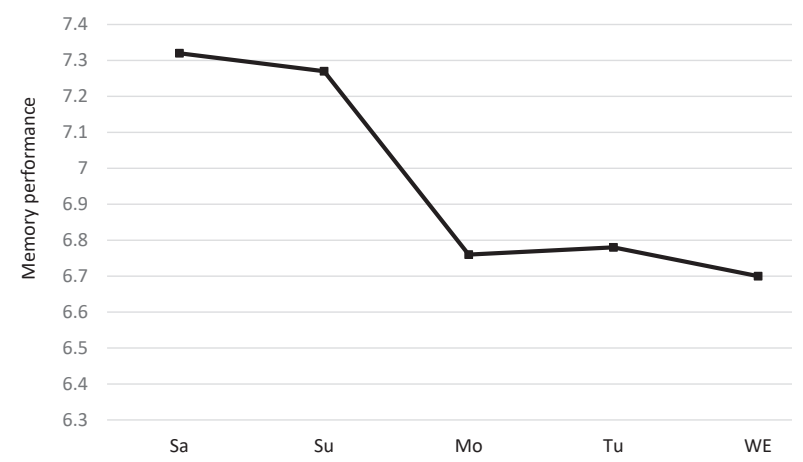

Figure 1. The Main Effect of the Weekly Cycle on the Memory Performance of Preschoolers. at 15 again. Chi Eta also reported in Table 3 for a daily cycle work suggests that about 17 percent of pre-school children's memory performance explained by daily cycle. Variance analysis results presented in Table 3 indicate that the interaction effect of daily cycles and groups on memory function in preschool children is significant, which means that the memory function of children in the morning, intermediate and evening groups during the different hours of the day is different from each other. Figure 3 depicts the interaction effect.

As Figure 3 indicates, there are differences regarding memory performance between children of different groups at different hours of the day. Morning preschool children are better than the other two groups at 8 o'clock in memory performance, but their performance drops at 11 and then remains relatively unchanged until 15 . Meanwhile, their worst performance in memory occurs at 15 , but this function is different for children at the intermediate and evening. These two groups have less memory performance at 8 oclock in the morning in

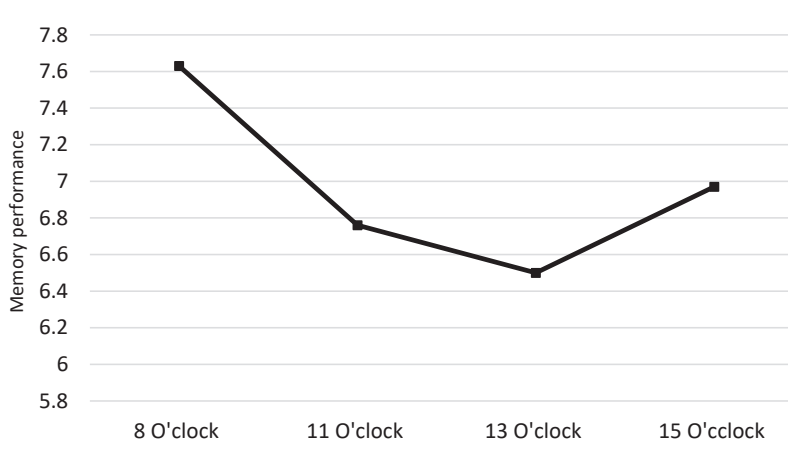

Figure 2. The Main Effect of the Daily Cycle on the Memory Performance of Preschoolers 


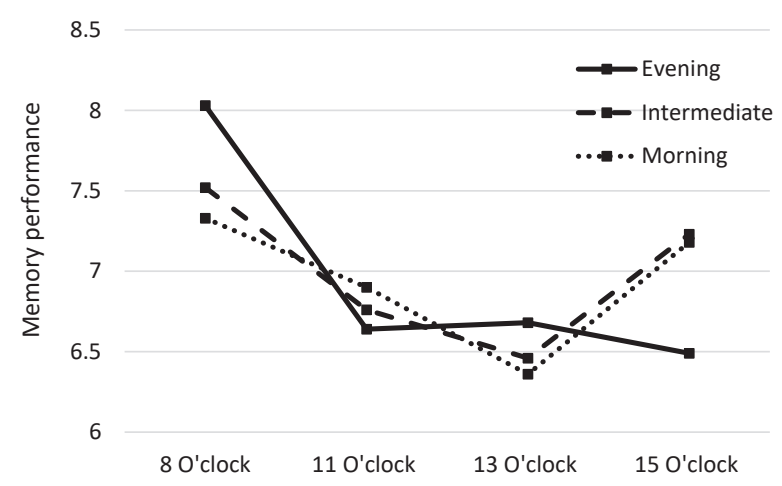

Figure 3. The Interactional Effect of Daily Cycle and Group on the Preschoolers' Memory Performance

comparison to the morning group, but as morning group their performance reduces from 11 to 13 . Unlike the morning group, their memory function improves at 15 compared to 13. Chi Eta also reported for the interaction effect of the weekly cycle and group on memory performance suggest that about $4 \%$ of preschoolers memory change explained by the weekly cycle.

According to Table 3 , it can see that the daily and weekly cycle interaction effect on memory function in preschool children is not significant, which means concerning all children, their performance at different times of the and in different days of the week does not differ significantly. However, according to the above table, it is observed that the interaction of the weekly cycle, daily cycles, and groups on memory performance is significant, which means that the performance of children in 3 groups, at different times for different days of the week have the same pattern. To illustrate this interaction, the interaction of the weekly cycle and the daily cycle of the 3 groups displayed in 4, 5 and 6 , respectively.

According to Figures 4 to 6 , it can be grasped that memory performance pattern of preschoolers morning, intermediate and evening during different times of different days of the week are different. For example, according to the diagrams, children in the morning have shown their best memory performance at $8 \mathrm{Am}$ all days of the week. However, this is not the case for the other two groups. The prominence of memory performance in the morning at 8 in the 2 groups no longer exists. Also, it can be seen that evening children's memory performance on all weekdays at 8 , and 15 is very close together and relatively constant during the week, while their performance at noon, at 11 and 13 , is gradually reduced during the week. However, this trend does not observe for the morning and intermediate, which means that in the two groups, especially in the morning, memory performances differences are relatively high throughout the week between 8 and 15 .

Another point is that evening children memory performance is relatively close and constant on the first

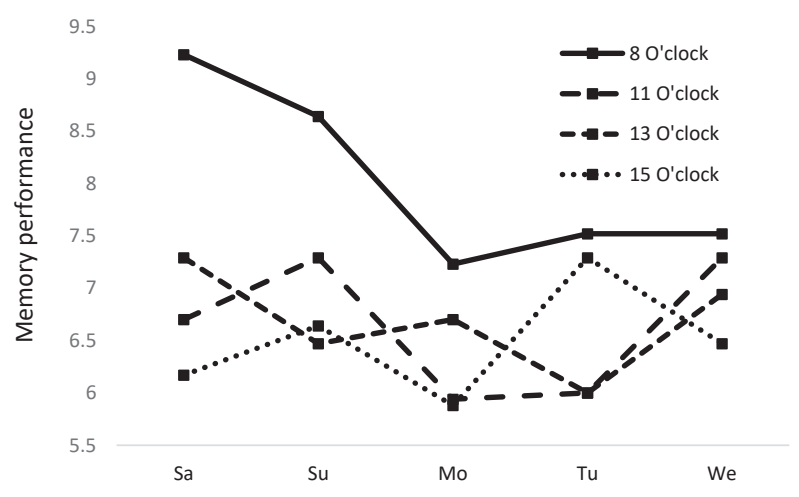

Figure 4. The Interactional Effect of Weekly Cycle and Daily Cycle on the Preschoolers' Memory Performance in the Morning Group.

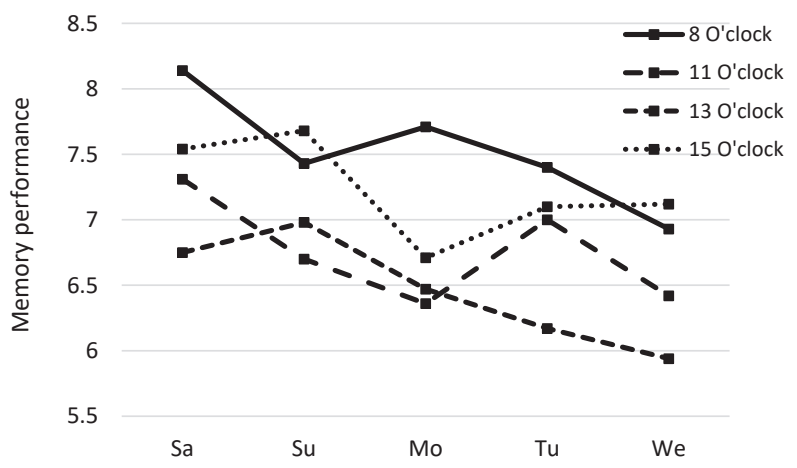

Figure 5. The Interactional Effect of Weekly Cycle and Daily Cycle on the Preschoolers' Memory Performance in the intermediate Group.

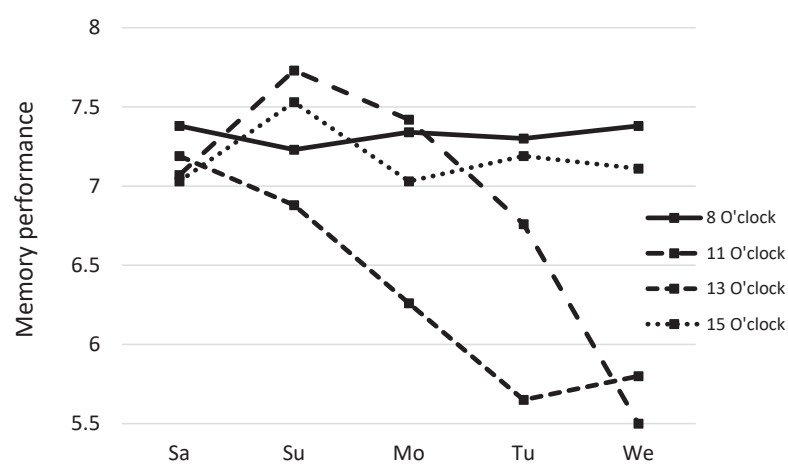

Figure 6. The Interactional Effect of Weekly Cycle and Daily Cycle on the Preschoolers' Memory Performance in the Evening Group.

day of the week at all hours of the day. Moreover, the next day, the difference in performance can be seen at different times of the day, while in the morning and evening there is a difference between the time of the day regarding memory performance from the beginning of the week. The best performance of morning and the intermediate group was at 8 oclock on Saturday, while the best performance for the evening group was on Sunday at $11 \mathrm{PM}$. A decline in memory function at noon, namely at 11 and 13, during 
the week was prominent for the intermediate group and very noticeable for evening group, while the morning group showed performance improvement in these two hours. Both the morning and the intermediate group showed the decline in memory performance in most of the hours on Monday, but the evening group unlike the other two depicted higher performance in most of the hours on Monday. Eta squared value reported for the interactive effect of daily and weekly cycles and group on memory performance States that the interaction of these 3 variables can explain about 3\% of preschoolers' changes in memory performance. According to the analysis done on memory performance scores, and based on the mixed analysis of variance, the first and second research questions will answer.

In response to the first research question, referring to the proving a significant main effect of the weekly and daily cycle on memory function, it concludes that memory function of preschool children in a learning environment is different throughout the day and week.

In response to the second research question, based on meaningful interaction between groups and daily cycles and also among the interaction effects of group, daily cycles and weekly cycle on memory performance, it can conclude memory performance of morning preschool children is different during the day and week in comparison to intermediate and even group at the same educational setting.

\section{Discussion}

This main aim of this research was to study the daily and weekly rhythm of working memory performance of preschoolers based on chronotype (morningness vs. eveningness). Analysis of the data in response to the first question showed that the memory performance of preschool children varies in a learning environment throughout the day and week. It also revealed that this difference of performance is significantly related to different days of the week. The findings of this study are in line with the results of Sharifi ${ }^{23}$ and Clark. ${ }^{5}$ In this study, preschool children had their highest memory performance on Saturdays and Sunday and the lowest cognitive performance on the weekends. However, in a study done by Sharifi, ${ }^{23}$ the children had shown lower cognitive performance on Saturday and Sunday and higher memory performance from Monday to Wednesday. Clark also mentioned maximum changes in the mood and weekly rhythms arousal on Fridays to Sunday and minimal changes observed from Monday to Wednesday. ${ }^{5}$ Fluctuations in the mental function of a child are in a daily cycle can be influenced by several factors including the daily social activities of a child, and emotional factors. ${ }^{13}$

The results of this study showed that preschoolers overall memory performance is different during different times of the day; this means that preschoolers memory performance at 8 oclock is at the highest level and the lowest level at 13 but it significantly improved at 15 in comparison to 13. The result of this study is not in line with the studies done by Sharifi, ${ }^{23}$ Esteki and Sadeghi, ${ }^{11}$ Valdez et $\mathrm{al},{ }^{24}$ Jarraya et $\mathrm{al},{ }^{25}$ but the present results are inconsistent with Jarraya et al. ${ }^{26}$

Sharifi in their study showed that the efficacy of the students is higher in the final hours before noon. ${ }^{23}$ Testu reported higher results in the morning than in the afternoon on working memory depends on the age of students. Results in the first and third class in the afternoon were markedly similar to the results in the morning. He states that efficiently cycle fluctuations influenced by external factors such as age, educational conditions, and other programs. ${ }^{27}$ Folkard and Monk ${ }^{28}$ showed superior working memory in the morning than in the afternoon. Valdes et $\mathrm{al}^{24}$ concluded that cognitive process improved during the day and reduced during the night and early morning, which means that students are not in good conditions to learn before $11 \mathrm{AM}$. Esteki and Sadeghi demonstrated the efficacy of visual working memory in girls was at its highest point at $4 \mathrm{pm}$ and for boys at 8 and 11 was higher than other times. ${ }^{11}$ Gaggioni et al in an explanation of the impact of sleep homeostasis and circadian rhythm on the brain's cognitive processes stated that brain cognitive activities that are light dependent as potent modulators of cognition and awareness directly affect sleep and the daily rhythms. So based on their results, it was expected that preschoolers have a lower memory performance in the morning and their performance increase at the mid-day when the sun is at its maximum, while the results showed the opposite. ${ }^{29}$

Jarraya et $\mathrm{al}^{25} \mathrm{Nicolas}^{30}$ Souissi et $\mathrm{al}^{31,32}$ showed the core body temperature depends on time and is at its maximum value at 16 which correlated with better cognitive performance. While Jarraya et al concluded that handball goalkeepers' cognitive function was related to the circadian rhythm which was higher in the morning than any other time. ${ }^{26}$ This finding is consistent with the findings of this research. On the other hand, most human activities show oscillations with a period of 24 hours by a biological clock that is at the core of the suprachiasmatic nucleus. Proof of the existence of this internal clock is that if a person placed in an environment with constant light and constant temperature, he will have the cycle of nearly 24 hours; therefore cognitive processes such as memory are different during 24 hours of a day. ${ }^{33}$ Data analysis in response to the second question showed that memory performance of morning preschool children is different throughout the day and week compared with intermediate and afternoon preschool children in an educational setting. The children in the morning, have always shown their best memory performance at 8 am all days of the week, But this is not the case for the other two groups. The prominence of the morning at 8 in the 2 groups no longer exists. This finding of this study is in line with the 
results obtained by Schmidt et al, ${ }^{9}$ Valdez et al, ${ }^{10}$ Konen et al, ${ }^{13}$ Diaz-Morales \& Escribano, ${ }^{12}$ Gaggioni et al, ${ }^{29}$ but in contrast with research done by Preckel et al. ${ }^{34}$ Preckel and colleagues demonstrated that cognitive ability positively correlated with the type of eveningness. This difference in preschool children better working memory performance with evening and evening groups can be because morning group go to bed earlier and get up earlier the day after and they do not hurry to eat breakfast, and we know that breakfast is essential for proper cognitive function properly during the day. ${ }^{34}$ Several studies have shown that individuals in evening groups have poor eating habits. They have difficulty to wake up in the morning and often leave the house without eating breakfast. The children who skip eating breakfast, avoiding being late to school, exposed more to health and performance problems. Not eating breakfast can decrease child school performance and reduces cognitive functioning. ${ }^{35,36}$ The evening group consumes fewer vegetables and more noodles; studies have shown that there is a correlation between eveningness preference and consumption of low-protein, calcium, zinc, vitamins $\mathrm{D}$ and $\mathrm{B} 6$, and riboflavin. ${ }^{37}$ As results the evening groups who have to wake up early in the morning, they will suffer from some sort of sleep deprivation, and their prefrontal cortex-related functions show significant impairments after sleep deprivation. ${ }^{38}$ However, the question is why individual morningness leads to excitement, wellbeing, and positive performance? One possibility is that morning people prefer to wake up early morning, and the expectations of society demand it, in contrast, as school working time begins in the early morning, eveningness group are forced to wake up earlier than their preferred time. Thus, they create a social jet lag, which leads to lack of sleep and distress in them. ${ }^{39}$

One of the limitations of this study includes the lack of sufficient literature to study working memory performance based on chronotype. According to the findings of this study, teachers and clinicians are suggested to consider the importance of circadian rhythm parameters in assessing cognitive function in patients and healthy people. Awareness of individual differences of the morningness-eveningness type can be very useful in designing training programs and preventive health associated matters with each type.

\section{Conflict of Interest Disclosures}

The authors declare that they have no conflict of interests.

\section{Ethical Statement}

The current research was approved by the local ethics committee of Shahid Beheshti University of Tehran.

\section{Acknowledgments}

As teenagers in the evening group have shown behavioral and educational-related problems, they can compare with their counterparts in the morning group. Thus, in future studies, the impact of chronotype (morningness evening) on academic performance and emotional and behavioral problems need to be investigated.

\section{References}

1. Van Dongen HP, Dinges DF. Circadian rhythms in fatigue, alertness, and performance. Principles and Practice of Sleep Medicine. 2000;20:391-399.

2. Best JR, Miller PH. A developmental perspective on executive function. Child Dev. 2010;81(6):1641-60. Doi: 10.1111/j.1467-8624.2010.01499.x.

3. Vallat-Azouvi C, Pradat-Diehl P, Azouvi P. Rehabilitation of the central executive of working memory after severe traumatic brain injury: two single-case studies. Brain Inj. 2009;23(6):585-594.

4. Yazdi-Ravandi S, Shamsaei F, Matinnia N, Moghimbeigi A, Shams J, Ahmadpanah $M$, et al. Executive functions, selective attention and information processing in patients with obsessive compulsive disorder: a study from west of Iran. Asian J Psychiatry. 2018;37:140-145.

5. Clark AV. Causes, Role, and Influence of Mood States. Nova Publishers; 2005.

6. Wright KP, Lowry CA, Le Bourgeois MK. Circadian and wakefulness-sleep modulation of cognition in humans. Front Mol Neurosci. 2012;5:50. doi: 10.3389/fnmol.2012.00050.

7. Cajochen C, Knoblauch V, Wirz-Justice A, Kräuchi K, Graw $P$, Wallach D. Circadian modulation of sequence learning under high and low sleep pressure conditions. Behav Brain Res. 2004;151(1):167-176. Doi:10.1016/j.bbr.2003.08.013.

8. Burke TM, Scheer FA, Ronda JM, Czeisler CA, Wright KP Jr. Sleep inertia, sleep homeostatic and circadian influences on higher-order cognitive functions. J Sleep Res. 2015;24(4):364371. doi: 10.1111/jsr.12291.

9. Schmidt C, Collette F, Cajochen C, Peigneux P. A time to think: circadian rhythms in human cognition. Cogn Neuropsychol. 2007 Oct;24(7):755-89. doi: 10.1080/02643290701754158.

10. Valdez P, Reilly $T$, Waterhouse J. Rhythms of mental performance. Mind, Brain, and Education. 2008;2(1):7-16.

11. Esteki M, Sadeghi D. Comparison of Short Term Memory Efficiency (Visual and Audio) at Circadian Rhythm (Chronopsychology). Procedia-Social and Behavioral Sciences. 2010;5:2002-2005. Doi:10.1016/j.sbspro.2010.07.404

12. Escribano C, Díaz-Morales JF. Daily fluctuations in attention at school considering starting time and chronotype: an exploratory study. Chronobiol Int. 2014;31(6):761-9. doi: 10.3109/07420528.2014.898649.

13. Konen T, Dirk J, Schmiedek F. Cognitive benefits of last night's sleep: daily variations in children's sleep behavior are related to working memory fluctuations. J Child Psychol Psychiatry. 2015;56(2):171-82. doi: 10.1111/jcpp.12296.

14. Goldstein D, Hahn CS, Hasher L, Wiprzycka UJ, Zelazo PD. Time of day, intellectual performance, and behavioral problems in Morning versus Evening type adolescents: Is there a synchrony effect? Pers Individ Dif. 2007;42(3):431-440.

15. Roenneberg T, Kuehnle T, Juda M, Kantermann T, Allebrandt K, Gordijn M, Merrow M. Epidemiology of the human circadian clock. Sleep Med Rev. 2007;11(6):429-438.

16. Adan A, Archer SN, Hidalgo MP, Di Milia L, NataleV, Randler C. Circadian typology: a comprehensive review. Chronobiol Int. 2012;29(9):1153-75. doi: 10.3109/07420528.2012.719971.

17. Cavanaugh LA, Cutright KM, Luce MF, Bettman JR. Hope, pride, and processing during optimal and nonoptimal times of day. Emotion. 2011;11(1):38-46.

18. Díaz-Morales JF, Escribano C. Consequences of adolescent's evening preference on psychological functioning: a review. Annals of Psychology. 2014;30(3):1096-1104.

19. Carrier J, Monk TH. Circadian rhythms of performance: new trends. Chronobiol Int. 2000;17(6):719-732.

20. Babkoff H, Caspy T, Hishikawa Y, Mikulincer M. Subjective 
sleepiness ratings: the effects of sleep deprivation, circadian rhythmicity and cognitive performance. Sleep. 1991;14(6):534-539.

21. Werner H, Molinari L, Guyer C, Jenni OG. Agreement rates between actigraphy, diary, and questionnaire for children's sleep patterns. Arch Pediatr Adolesc Med. 2008;162(4):3508. doi: 10.1001/archpedi.162.4.350.

22. Carskadon MA, Vieira C, Acebo C. Association between puberty and delayed phase preference. Sleep. 1993;16(3):258262.

23. Sharifi M. Psychological time: A study of daily and weekly changes in the attention and subjective activities of primary school students. J Psychol. 1998;2(6):178-199.

24. Valdez P, Ramírez C, García A. Circadian rhythms in cognitive processes: implications for school learning. Mind, Brain, and Education. 2014;8(4):161-168. doi: 10.1111/mbe.12056.

25. Jarraya S, Jarraya $M$, Souissi N. Diurnal variations of cognitive performances in Tunisian children. Biol Rhythm Res. 2014;45(1):61-67. Doi:10.1080/09291016.2013.797640.

26. Jarraya S, Jarraya M, Chtourou H, Souissi N. Diurnal variations on cognitive performances in handball goalkeepers. Biol Rhythm Res. 2014;45(1):93-101.

27. Testu F. School Rhythms. French Journal of Pedagogy. 1979;47:47-58.

28. Folkard S, Monk TH. Circadian rhythms in human memory. $\mathrm{Br}$ J Psychol. 1980 May; 71(2):295-307.

29. Gaggioni G, Maquet P, Schmidt C, Dijk DJ, Vandewalle G. Neuroimaging, cognition, light and circadian rhythms. Front Syst Neurosci. 2014;8:126. doi: 10.3389/fnsys.2014.00126.

30. Nicolas A, Gauthier A, Bessot N, Moussay S, Davenne D. Time-of-day effects on myoelectric and mechanical properties of muscle during maximal and prolonged isokinetic exercise. Chronobiol Int. 2005;22(6):997-1011.

31. Souissi H, Chtourou H, Chaouachi A, Chamari K, Souissi N,
Amri M. Time-of-day effects on EMG parameters during the Wingate test in boys. J Sports Sci Med. 2012 Sep 1;11(3):3806 .

32. Souissi H, Chtourou H, Chaouachi A, Dogui M, Chamari K, Souissi $\mathrm{N}$, et al. The effect of training at a specific time-of-day on the diurnal variations of short-term exercise performances in 10-to 11-year-old boys. Pediatr Exerc Sci. 2012;24(1):8499.

33. Russell F, Kreitzman, L. Seasons of Life: The Biological Rhythms That Living Things Need to Thrive and Survive. Yale University Press; 2009.

34. Preckel F, Lipnevich AA, Schneider S, Roberts RD. Chronotype, cognitive abilities, and academic achievement: A metaanalytic investigation. Learn Individ Differ. 2011;21(5):483492.

35. Randler C, Frech D. Young people's time-of-day preferences affect their school performance. J Youth Stud. 2009;12(6):653667.

36. Schmidt S, Randler C. Morningness-Eveningness and eating disorders in a sample of adolescent girls. J Individ Differ. 2010;31(1):38-45.

37. Sato-Mito N, Shibata S, Sasaki S, Sato K. Dietary intake is associated with human chronotype as assessed by both morningness-eveningness score and preferred midpoint of sleep in young Japanese women. Int J Food Sci Nutr. 2011;62(5):525-32. doi: 10.3109/09637486.2011.560563

38. Blatter K, Cajochen C. Circadian rhythms in cognitive performance: methodological constraints, protocols, theoretical underpinnings. Physiol Behav. 2007;90(2):196208.

39. Wittmann M, Dinich J, Merrow M, Roenneberg T. Social jetlag: misalignment of biological and social time. Chronobiol Int. 2006;23(1-2):497-509. 